\title{
Brain regions associated with anosognosia for memory disturbance in Alzheimer's disease: a magnetic resonance imaging study
}

This article was published in the following Dove Press journal:

Neuropsychiatric Disease and Treatment

5 July 2017

Number of times this article has been viewed

\author{
Hiroshi Fujimoto' \\ Teruyuki Matsuoka' \\ Yuka Kato' \\ Keisuke Shibata' \\ Kaeko Nakamura' \\ Kei Yamada ${ }^{2}$ \\ Jin Narumoto'
}

'Department of Psychiatry, Graduate School of Medical Science, Kyoto Prefectural University of Medicine, Kyoto, Japan; ${ }^{2}$ Department of Radiology, Graduate School of Medical Science, Kyoto Prefectural University of Medicine, Kyoto, Japan
Correspondence: Teruyuki Matsuoka Department of Psychiatry, Graduate School of Medical Science, Kyoto Prefectural University of Medicine, 465 Kajii-cho, Kawaramachi-Hirokoji, Kamigyo-ku, Kyoto 602-8566, Japan Tel $+817525 I 5612$

Fax +81752515839

Email tmms2004@koto.kpu-m.ac.jp
Background and objective: Patients with Alzheimer's disease (AD) are frequently unaware of their cognitive symptoms and medical diagnosis. The term "anosognosia" is used to indicate a general lack of awareness of one's disease or disorder. The neural substrate underlying anosognosia in AD is unclear. Since anosognosia for memory disturbance might be an initial sign of $\mathrm{AD}$, it is important to determine the neural correlates. This study was designed to investigate the characteristics and neural correlates of anosognosia for memory disturbance in patients with mild AD.

Methods: The subjects were 49 patients with mild AD who participated in a retrospective cross-sectional study. None of the patients had been treated with cholinesterase inhibitors, memantine, or psychotropic drugs. All patients underwent magnetic resonance imaging (MRI). Anosognosia for memory disturbance was assessed based on the discrepancy between questionnaire scores of patients and their caregivers. Structural MRI data were analyzed to explore the association between anosognosia and brain atrophy, using a voxel-based approach. Statistical parametric mapping software was used to explore neural correlations. In image analysis, multiple regression analysis was performed to examine the relationship between anosognosia score and regional gray matter volume. Age, years of education, and total intracranial volume were entered as covariates.

Results: The anosognosia score for memory disturbance was significantly negatively correlated with gray matter volume in the left superior frontal gyrus.

Conclusion: The left superior frontal gyrus was involved in anosognosia for memory disturbance, while the medial temporal lobe, which is usually damaged in mild AD, was not associated with anosognosia. The left superior frontal gyrus might be an important region for anosognosia in mild AD.

Keywords: anosognosia, Alzheimer's disease, MRI, superior frontal gyrus

\section{Introduction}

Patients with neurological disorders are frequently unaware of their cognitive and behavioral symptoms. The term "anosognosia" was originally used by Babinski in 1914 to describe patients with lack of awareness of hemiplegia, but now is used to denote general unawareness of one's disease or impairments. Anosognosia is a common symptom in patients with Alzheimer's disease (AD) ${ }^{1,2}$ and affects treatment and care of AD. From a clinical perspective, anosognosia in AD is associated with psychiatric symptoms, behavioral disturbances, and caregiver burden. ${ }^{3,4}$

In the early stages of $\mathrm{AD}$, most patients have some insight into their cognitive dysfunction. However, as the disease progresses, the consciousness of disease often 
disappears and patients may become indifferent to their clinical condition. ${ }^{1,5,6}$ AD patients with anosognosia cannot recognize a lack or absence of insight in impairments of activities of daily living (ADL) or cognitive dysfunction, particularly in the memory domain. ${ }^{7}$ Anosognosia for memory disturbance occurs about 2-3 years before dementia onset, ${ }^{8}$ indicating that anosognosia might be an early sign of AD.

The brain substrates in anosognosia in AD have not been fully determined. Neuroimaging studies using fluorodeoxyglucose positron emission tomography, single photon emission computed tomography (SPECT), and functional magnetic resonance imaging (fMRI) have shown a relationship between anosognosia for memory disturbance in AD and dysfunction in the frontal and temporoparietal regions. ${ }^{9-19}$ To our knowledge, the structural brain substrates of anosognosia for memory disturbance in AD have not been examined. Since anosognosia for memory disturbance might be an early sign of $\mathrm{AD}$, it is important to define the neural correlates. Therefore, the objective of this study is to investigate the structural neural correlates of anosognosia for memory disturbance in mild AD, using MRI.

\section{Methods}

\section{Participants}

The subjects were 49 patients (16 males and 33 females) who visited the Center for Diagnosis of Dementia at Kyoto Prefectural University of Medicine and were diagnosed with AD, based on National Institute of Neurological and Communicative Disorders and Stroke-Alzheimer's Disease and Related Disorders Association criteria for probable AD ${ }^{20}$ To ascertain the diagnosis of $\mathrm{AD}$, all the subjects were assessed comprehensively by geriatric psychiatrists using medical and social histories, physical and neurological examinations, neuropsychological tests, laboratory data, and brain imaging. Only patients with mild AD, defined by a score of $\geq 17$ on the mini mental state examination (MMSE), ${ }^{21}$ were included in the study. Patients with a significant history of psychiatric or neurological disorders, including stroke, head injury, epilepsy, psychiatric disorders, alcohol abuse, evidence of use of psychoactive substances, or a serious medical condition were excluded. None of the subjects had been treated with cholinesterase inhibitors, memantine, or psychotropic drugs because our center examines patients without a diagnosis. All subjects underwent assessment of anosognosia, neuropsychiatric tests, and brain MRI. Medical charts of the subjects were reviewed and data obtained at the first visit were used. The time between assessments and brain MRI was $<1$ month. This retrospective cross-sectional study was approved by the Ethics Committee of Kyoto Prefectural University of Medicine. Since this study was a retrospective study, a requirement for written informed consent was waived by the ethics committee. Instead of written informed consent, information on this study was made available in the waiting room of our outpatient clinic and on our institutional home page. In addition, information on the right to opt out of the study was also presented. If the subjects hoped to opt out of the study, the subjects were excluded from this study.

\section{Quantitative assessment of anosognosia for memory disturbance}

All patients were given a questionnaire adapted from Squire and Zouzounis. ${ }^{22}$ The anosognosia score was calculated as described in a previous study. ${ }^{23}$ The questionnaire includes 20 items reflecting different aspects of memory function. Patients and caregivers rated each item separately using a 9-point scale from -4 (worst) to +4 (best) for comparison of the patient's current ability level to that of 5 years ago. Therefore, the total scores range from -80 to +80 . To derive the anosognosia score, the total caregiver score was subtracted from the total patient score. The resulting anosognosia score could range from -160 to +160 , with a higher score indicating less awareness of memory deficits. These scores have previously been shown to be reliable in patients with dementia. ${ }^{1,24-26}$

\section{Cognitive and neuropsychiatric assessments}

The MMSE and Clinical Dementia Rating ${ }^{27,28}$ were used for assessment of global cognitive deficits and severity of dementia. Psychiatric symptoms were assessed with the Neuropsychiatric Inventory (NPI), on which the greater the score, the higher would be the severity or frequency. ${ }^{29,30}$ The NPI evaluates 12 neuropsychiatric symptoms in dementia: delusions, hallucinations, agitation, depression, anxiety, euphoria, apathy, disinhibition, irritability, aberrant motor behavior, sleep disturbance, and eating problems. The Geriatric Depression Scale (GDS) is a self-rating scale with 15 questions for depression, ${ }^{31,32}$ on which the higher the score, the more the severity of depression.

\section{Magnetic resonance imaging acquisition and analysis}

MRI was performed on a 3.0T clinical scanner with an 8-channel phased-array head coil (Philips Achieva 3.0 TX; Royal Philips, Amsterdam, the Netherlands). A T1-3D gradient echo (similar to magnetization-prepared rapid gradient-echo) sequence was used to generate 200 contiguous $0.9-\mathrm{mm}$ axial 
slices (repetition time $[\mathrm{TR}]=6.9 \mathrm{~ms}$; echo time $[\mathrm{TE}]=3.3 \mathrm{~ms}$; field of view $[\mathrm{FOV}]=250 \mathrm{~mm}$; matrix size $=256 \times 256$ ). Voxel-based morphometry (VBM) analysis was performed using Statistical Parametric Mapping (SPM) 12 (Wellcome Department of Cognitive Neurology, University College, London, UK) in Matlab R2015b (Mathworks Inc., Sherborn, MA, USA). First, a visual check was performed to ensure quality, and the origin of each image was oriented to the anterior commissure-posterior commissure line using the SPM "check reorientation" function. Next, the images were registered and segmented using the diffeomorphic anatomical registration through exponentiated lie algebra algorithm, and normalized to Montreal Neurological Institute (MNI) space. In this process, the images were bias-corrected. The affine regularization space template from the International Consortium for Brain Mapping was changed from "European brain" to "East Asian brain" because all the subjects in this study were Japanese. Finally, the images were smoothed using an 8 -mm full width at half maximum filter. ${ }^{33}$

\section{Statistical analysis}

Statistical analyses were performed with SPSS 23 for Windows (SPSS Inc., Chicago, IL, USA). Comparisons between males and females were performed using independent group $t$-tests and Mann-Whitney $U$ tests. Spearman rank correlation coefficient analysis was used to evaluate relationships of anosognosia scores with patient characteristics and psychiatric symptoms. The significance level was set at $P=0.05$. In image analysis, multiple regression analysis was performed over the whole brain to examine the relationship between anosognosia score and regional gray matter volume. Age, years of education, and total intracranial volume (calculated as the sum of gray matter, white matter, and cerebrospinal fluid volume, used as a surrogate for head size) were used in this analysis as covariates. Therefore, the analysis was performed while controlling for the effects of demographical variables and total intracranial volume. The $\mathrm{X}, \mathrm{Y}$, and $\mathrm{Z}$ coordinates provided by SPM were used to approximate the MNI brain space. The initial voxel threshold was set to an uncorrected $P$-value of 0.001 . Clusters were considered to be significant when falling below a cluster corrected $P$-value (false discovery rate) $)^{34}$ of 0.05 .

\section{Results}

\section{Demographic and neuropsychological characteristics}

The demographic and neuropsychological characteristics of participants are shown in Table 1. The subjects comprised 16 males and 33 females (Table 2). There were no significant
Table I Demographic and neuropsychological characteristics of participants (33 females, 16 males)

\begin{tabular}{lll}
\hline Characteristic & Range & Mean \pm SD \\
\hline Age (years) & 67 to 89 & $79.1 \pm 5.1$ \\
Education (years) & 6 to 16 & $11.1 \pm 2.5$ \\
Mini-mental state examination & 17 to 28 & $21.6 \pm 2.9$ \\
Total intracranial volume $\left(\mathrm{cm}^{3}\right)$ & 1,138 to 1,567 & $1,313.1 \pm 97.1$ \\
Clinical dementia rating & 0.5 to I & $0.9 \pm 0.2$ \\
Anosognosia score & -16 to 62 & $21.4 \pm 17.2$ \\
Patient self-rating score & -33 to 0 & $-12.6 \pm 8.5$ \\
Caregiver score & -77 to 7 & $-33.9 \pm 15.9$ \\
NPI apathy subscale score & 0 to 12 & $1.5 \pm 2.9$ \\
Geriatric depression scale & 0 to 12 & $4.1 \pm 3.2$ \\
\hline
\end{tabular}

Note: Data are shown as mean \pm SD.

Abbreviation: NPI, neuropsychiatric inventory.

differences in anosognosia scores between males and females. Total intracranial volume differed significantly between males and females. Anosognosia scores showed no significant correlations with patient characteristics (Table 3). Among psychiatric symptoms, GDS scores $(r=-0.389, P<0.01)$ were negatively correlated with anosognosia scores (Table 3 ).

\section{VBM results}

In multiple regression analysis using age, years of education, and total intracranial volume as covariates, the anosognosia score for memory disturbance was significantly negatively correlated only with gray matter volume in the left superior frontal gyrus (cluster size $[k]=650$, volume $=2,193.75 \mathrm{~mm}^{3}$, Brodmann areas $6 / 8$, MNI coordinates of peak voxels $-15.0 / 18.0 / 56.0)$ (Figure 1). The same findings were obtained including GDS as an additional covariate, but the clusters were smaller (cluster size $[k]=372$, volume $=1,255.5 \mathrm{~mm}^{3}$, Brodmann areas $6 / 8$, MNI coordinates of peak voxels $-15.0 / 18.0 / 56.0$ ).

Table 2 Comparison between males and females

\begin{tabular}{llll}
\hline Characteristics & $\begin{array}{l}\text { Male } \\
(\mathbf{n}=\mathbf{1 6})\end{array}$ & $\begin{array}{l}\text { Female } \\
(\mathbf{n}=\mathbf{3 3})\end{array}$ & P-value \\
\hline Age (years) & $77.6 \pm 5.1$ & $79.9 \pm 5.0$ & 0.093 \\
Education (years) & $12.0 \pm 3.1$ & $10.6 \pm 2.0$ & 0.121 \\
Mini-mental state examination & $22.1 \pm 2.8$ & $21.4 \pm 2.9$ & 0.499 \\
Total intracranial volume $\left(\mathrm{cm}^{3}\right)$ & $1,391.1 \pm 82.8$ & $1,275.3 \pm 80.1$ & $<0.01$ \\
Clinical dementia rating & $0.8 \pm 0.2$ & $1.0 \pm 0.1$ & 0.062 \\
Anosognosia score & $20.4 \pm 19.3$ & $21.9 \pm 16.4$ & 0.685 \\
Patient self-rating score & $-11.9 \pm 9.4$ & $-12.9 \pm 8.2$ & 0.501 \\
Caregiver-rating score & $-32.3 \pm 16.8$ & $-34.7 \pm 15.7$ & 0.481 \\
NPI apathy subscale score & $1.4 \pm 2.0$ & $1.6 \pm 3.3$ & 0.798 \\
Geriatric depression scale & $3.6 \pm 3.2$ & $4.3 \pm 3.1$ & 0.379 \\
\hline
\end{tabular}

Note: Data are shown as mean \pm SD.

Abbreviation: NPI, neuropsychiatric inventory. 
Table 3 Correlations between the anosognosia score, patients' characteristics, and psychiatric symptoms

\begin{tabular}{ll}
\hline Characteristics & $\boldsymbol{R}$ \\
\hline Age (years) & 0.213 \\
Education (years) & -0.168 \\
Mini-mental state examination & -0.182 \\
Total intracranial volume $\left(\mathrm{cm}^{3}\right)$ & -0.238 \\
NPI apathy subscale score & $0.08 \mathrm{I}$ \\
Geriatric depression scale & $-0.389 *$ \\
\hline
\end{tabular}

Note: $* P<0.01$.

Abbreviation: NPI, neuropsychiatric inventory.

\section{Discussion}

The characteristics and neural correlates of anosognosia for memory disturbance in patients with mild $\mathrm{AD}$ were investigated in this study. The left superior frontal gyrus was involved in anosognosia for memory disturbance. The medial temporal lobe, which is usually damaged in mild AD, was not associated with anosognosia. Depressive symptoms affected anosognosia for memory disturbance in $\mathrm{AD}$, but other psychiatric symptoms and gender did not do so. However, even after elimination of the effect of depression, the left superior frontal gyrus was still involved in anosognosia. Therefore, the left superior frontal gyrus can be considered to be an important region for anosognosia in mild AD.

Previous neuroimaging studies have explored neural correlates of anosognosia in dementia, but the results have not been fully consistent. This might be due to use of different research methods. First, anosognosia can be measured in relation to different cognitive and behavioral domains (ie, memory, behavior, and functioning in ADL). Some studies have shown the importance of a specific cognitive domain, such as memory impairment, whereas others have addressed awareness in a wider context, involving impaired awareness of cognitive, behavioral, and functional disorder. Second, most studies included only patients with $\mathrm{AD}$, while others included patients with several neurodegenerative conditions (ie, mild cognitive impairment and frontotemporal dementia). These differences in subjects may be associated with different patterns of brain correlates. Third, most initial studies used a region of interest (ROI) approach and focused on the frontal region. ${ }^{9-12,35-37}$ Therefore, interpretation of these results is limited by the criteria used to define ROIs. Even in the era of whole-brain voxel-based approaches, some studies show involvement of frontal regions. However, other studies at the whole-brain level have shown the involvement of more posterior regions, including medial parietal (precuneus and posterior cingulate), lateral parietal and temporal areas. ${ }^{37-39}$ These results show a disparate range of brain correlates, but mainly localized in the frontal and temporoparietal regions. Interestingly, previous VBM studies showed that anosognosia in schizophrenia is also associated with the frontal and temporoparietal regions. ${ }^{40-44}$ Therefore, these regions might be involved in anosognosia, regardless of the disease.

Since memory disturbance is a core symptom of AD, some studies have assessed anosognosia for memory disturbance. Shibata et al used SPECT to identify a region in the left orbitofrontal cortex where perfusion correlated with anosognosia for memory disturbance..$^{15}$ In the
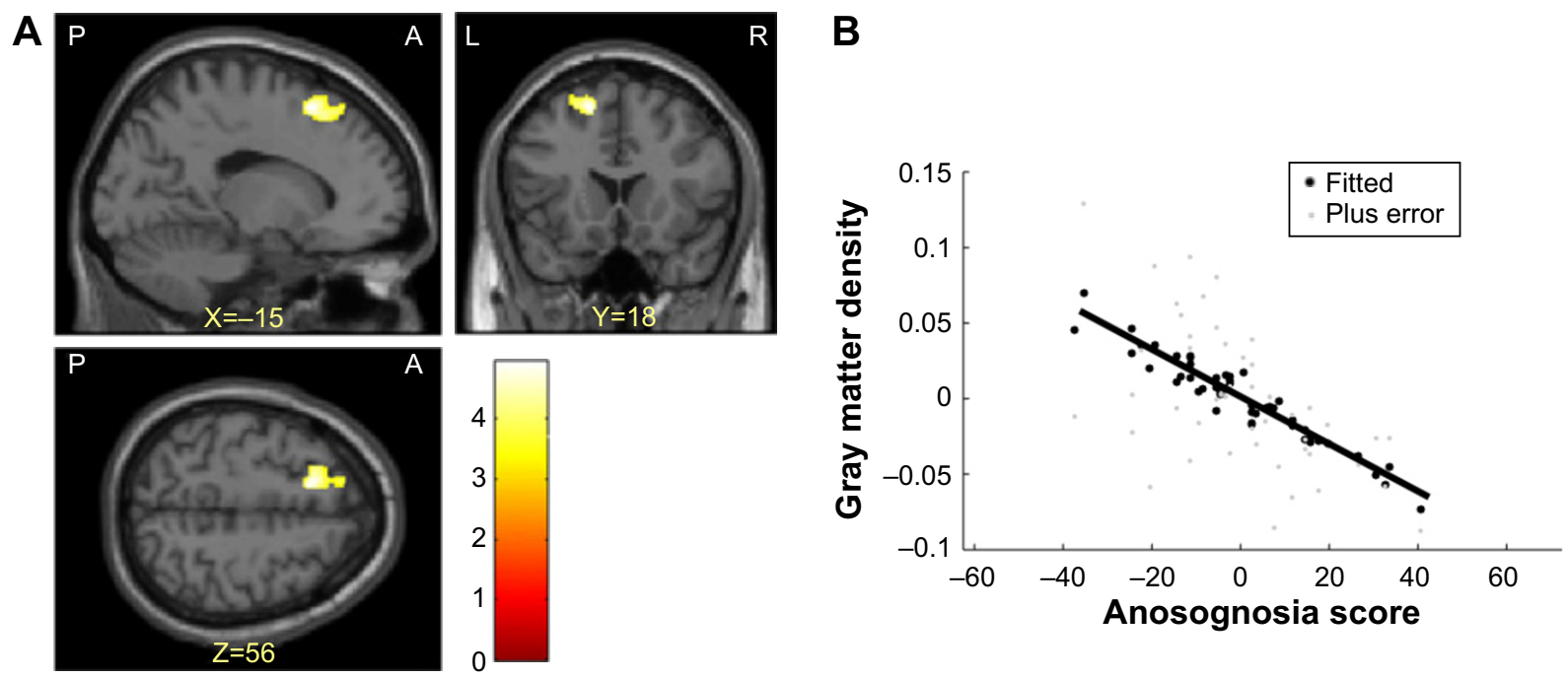

Figure I (A) Regions in which there were significant negative correlations between gray matter density and anosognosia scores using age, years of education, and total intracranial volume as covariates. The left superior frontal gyrus is visualized at the $P<0.001$ uncorrected level. This region survived the false discovery rate cluster level correction for multiple comparisons at $P<0.05$. (B) Correlation between gray matter density in the left superior frontal gyrus and anosognosia score at the voxel showing a maximum peak.

Abbreviations: $\mathrm{P}$, posterior; A, anterior; L, left; $\mathrm{R}$, right. 
current study, anosognosia in patients with mild AD was correlated with damage in the left superior frontal gyrus, which is not a brain region involved in early symptoms of $\mathrm{AD}$, including disturbance of memory, disorientation, and visuospatial ability. Indeed, anosognosia scores were not associated with dementia severity or cognitive impairment. This suggests that anosognosia for memory disturbances in the early stages of $\mathrm{AD}$ is associated with other aspects of cognitive impairment.

The left superior frontal gyrus was correlated with anosognosia for memory disturbance in this study. Previous fMRI studies have shown activities of this region, including mediation of aspects of self-relevant information in healthy subjects $^{45}$ and as a specific marker of feigned memory impairment in normal people. ${ }^{46}$ In a default mode network (DMN) activity study, functional connectivity between the left superior frontal gyrus, right superior frontal gyrus, and posterior cingulate cortex was lower in patients with $\mathrm{AD}$ than in controls. ${ }^{47}$ Several resting state fMRI studies have shown that DMN activity is reduced in AD. ${ }^{48,49}$ These regions in DMN resemble those concerned with self-appraisal in taskrelated fMRI. ${ }^{37,50,51}$ Since fMRI studies have indicated that the left superior frontal gyrus, which is one of the regions in $\mathrm{DMN}$, is involved in self-awareness, AD patients with damage to this brain region might have anosognosia.

Anosognosia, apathy, and depression are common manifestations in $\mathrm{AD} .{ }^{52,53} \mathrm{We}$ found that severity of depression was negatively correlated with the degree of anosognosia in AD. Thus, AD patients with milder depression have severer anosognosia. Mild depression may constitute an emotional reaction to the awareness of cognitive dysfunction. As the insight of a patient decreases, the patient may become indifferent to their condition and may not feel depression and anxiety. The results of the current study concur with those of previous studies. ${ }^{6,54}$ In contrast, we did not find significant associations between anosognosia and apathy in AD. In an 18-month longitudinal study, patients with anosognosia at baseline had a significant increase in apathy scores during follow-up, compared with patients without anosognosia. ${ }^{53}$ Previous studies of the relationship between apathy and anosognosia in $\mathrm{AD}$ and MCI suggest that apathy manifests at later stages of neurodegeneration. ${ }^{55,56}$ Therefore, the current cross-sectional study in the early stages of AD might not have been able to identify this relationship between apathy and anosognosia, and longitudinal studies are required for this purpose.

\section{Limitation}

A limitation of this study is that we focused on anosognosia for memory disturbance. Results may differ in anosognosia for other disorders, such as behavioral disorder. The retrospective cross-sectional design is a further limitation. However, this study is the first to show that atrophy in the left superior frontal gyrus might affect anosognosia for memory disturbance in mild AD. Longitudinal studies of the relationship between anosognosia and brain regions are needed to define the basis of anosognosia in AD.

\section{Disclosure}

The authors report no conflicts of interest in this work.

\section{References}

1. Starkstein SE, Jorge R, Mizrahi R, Robinson RG. A diagnostic formulation for anosognosia in Alzheimer's disease. J Neurol Neurosurg Psychiatry. 2006;77(6):719-725.

2. Mograbi DC, Ferri CP, Sosa AL, et al. Unawareness of memory impairment in dementia: a population-based study. Int Psychogeriatr. 2012;24(6):931-939.

3. Al-Aloucy MJ, Cotteret R, Thomas P, Volteau M, Benmaou I, Dalla Barba G. Unawareness of memory impairment and behavioral abnormalities in patients with Alzheimer's disease: relation to professional health care burden. J Nutr Health Aging. 2011;15(5):356-360.

4. Vogel A, Waldorff FB, Waldemar G. Impaired awareness of deficits and neuropsychiatric symptoms in early Alzheimer's disease: the Danish Alzheimer Intervention Study (DAISY). J Neuropsychiatry Clin Neurosci. 2010;22(1):93-99.

5. Aalten P, van Valen E, de Vugt ME, Lousberg R, Jolles J, Verhey FR. Awareness and behavioral problems in dementia patients: a prospective study. Int Psychogeriatr. 2006;18(1):3-17.

6. Clare L, Nelis SM, Martyr A, et al. The influence of psychological, social and contextual factors on the expression and measurement of awareness in early-stage dementia: testing a biopsychosocial model. Int J Geriatr Psychiatry. 2012;27(2):167-177.

7. Orfei MD, Varsi AE, Blundo C, et al. Anosognosia in mild cognitive impairment and mild Alzheimer's disease: frequency and neuropsychological correlates. Am J Geriatr Psychiatry. 2010;18(12):1133-1140.

8. Wilson RS, Boyle PA, Yu L, et al. Temporal course and pathologic basis of unawareness of memory loss in dementia. Neurology. 2015;85(11): 984-991.

9. Ott BR, Noto RB, Fogel BS. Apathy and loss of insight in Alzheimer's disease: a SPECT imaging study. J Neuropsychiatry Clin Neurosci. 1996;8(1):41-46.

10. Derouesne C, Thibault S, Lagha-Pierucci S, Baudouin-Madec V, Ancri D, Lacomblez L. Decreased awareness of cognitive deficits in patients with mild dementia of the Alzheimer type. Int $J$ Geriatr Psychiatry. 1999;14(12):1019-1030.

11. Harwood DG, Sultzer DL, Feil D, Monserratt L, Freedman E, Mandelkern MA. Frontal lobe hypometabolism and impaired insight in Alzheimer disease. Am J Geriatr Psychiatry. 2005;13(11):934-941.

12. Vogel A, Hasselbalch SG, Gade A, Ziebell M, Waldemar G. Cognitive and functional neuroimaging correlate for anosognosia in mild cognitive impairment and Alzheimer's disease. Int J Geriatr Psychiatry. 2005;20(3):238-246.

13. Salmon E, Perani D, Herholz K, et al. Neural correlates of anosognosia for cognitive impairment in Alzheimer's disease. Hum Brain Mapp. 2006;27(7):588-597.

14. Mimura M. Memory impairment and awareness of memory deficits in early-stage Alzheimer's disease. Tohoku J Exp Med. 2008;215(2): 133-140.

15. Shibata K, Narumoto J, Kitabayashi Y, Ushijima Y, Fukui K. Correlation between anosognosia and regional cerebral blood flow in Alzheimer's disease. Neurosci Lett. 2008;435(1):7-10. 
16. Amanzio M, Torta DM, Sacco K, et al. Unawareness of deficits in Alzheimer's disease: role of the cingulate cortex. Brain. 2011;134(Pt 4): 1061-1076.

17. Zamboni G, Drazich E, McCulloch E, et al. Neuroanatomy of impaired self-awareness in Alzheimer's disease and mild cognitive impairment. Cortex. 2013;49(3):668-678.

18. Jedidi H, Feyers D, Collette F, et al. Dorsomedial prefrontal metabolism and unawareness of current characteristics of personality traits in Alzheimer's disease. Soc Cogn Affect Neurosci. 2014;9(10): 1458-1463.

19. Perrotin A, Desgranges B, Landeau B, et al. Anosognosia in Alzheimer disease: disconnection between memory and self-related brain networks. Ann Neurol. 2015;78(3):477-486.

20. McKhann G, Drachman D, Folstein M, Katzman R, Price D, Stadlan EM. Clinical diagnosis of Alzheimer's disease: report of the NINCDSADRDA work group under the auspices of department of health and human services task force on Alzheimer's disease. Neurology. 1984;34(7):939-944.

21. Folstein MF, Folstein SE, McHugh PR. "Mini-mental state". A practical method for grading the cognitive state of patients for the clinician. J Psychiatr Res. 1975;12(3):189-198.

22. Squire LR, Zouzounis JA. Self-ratings of memory dysfunction: different findings in depression and amnesia. J Clin Exp Neuropsychol. 1988;10(6):727-738.

23. Michon A, Deweer B, Pillon B, Agid Y, Dubois B. Relation of anosognosia to frontal lobe dysfunction in Alzheimer's disease. J Neurol Neurosurg Psychiatry. 1994;57(7):805-809.

24. Snow AL, Norris MP, Doody R, Molinari VA, Orengo CA, Kunik ME. Dementia deficits scale. Rating self-awareness of deficits. Alzheimer Dis Assoc Disord. 2004;18(1):22-31.

25. Migliorelli R, Teson A, Sabe L, et al. Anosognosia in Alzheimer's disease: a study of associated factors. J Neuropsychiatry Clin Neurosci. 1995;7(3):338-344.

26. Mangone CA, Hier DB, Gorelick PB, et al. Impaired insight in Alzheimer's disease. J Geriatr Psychiatry Neurol. 1991;4(4):189-193.

27. Morris JC. The Clinical Dementia Rating (CDR): current version and scoring rules. Neurology. 1993;43(11):2412-2414.

28. Hughes CP, Berg L, Danziger WL, Coben LA, Martin RL. A new clinical scale for the staging of dementia. Br J Psychiatry. 1982;140: 566-572.

29. Cummings JL. The Neuropsychiatric inventory: assessing psychopathology in dementia patients. Neurology. 1997;48(5 Suppl 6):S10-S16.

30. Hirono N, Mori E, Ikejiri Y, et al. Japanese version of the Neuropsychiatric Inventory - a scoring system for neuropsychiatric disturbance in dementia patients. No To Shinkei. 1997;49(3):266-271.

31. Sheikh JI, Yesavage JA. Geriatric Depression Scale (GDS): recent evidence and development of a shorter version. Clin Gerontol. 1986;5: $165-173$.

32. Watanabe M, Imagawa T. Factor structure of the short form of the geriatric depression scale (GDS): reliability, validity and cutoff points. Jpn J Pers. 2013;22:193-197. Japanese.

33. Ashburner J. A fast diffeomorphic image registration algorithm. Neuroimage. 2007;38(1):95-113.

34. Chumbley JR, Friston KJ. False discovery rate revisited: FDR and topological inference using gaussian random fields. Neuroimage. 2009; 44(1):62-70.

35. Starkstein SE, Vazquez S, Migliorelli R, Teson A, Sabe L, Leiguarda R. A single-photon emission computed tomographic study of anosognosia in Alzheimer's disease. Arch Neurol. 1995;52(4):415-420.

36. Marshall GA, Kaufer DI, Lopez OL, Rao GR, Hamilton RL, DeKosky ST. Right prosubiculum amyloid plaque density correlates with anosognosia in Alzheimer's disease. J Neurol Neurosurg Psychiatry. 2004; 75(10):1396-1400.

37. Ries ML, Jabbar BM, Schmitz TW, et al. Anosognosia in mild cognitive impairment: relationship to activation of cortical midline structures involved in self-appraisal. J Int Neuropsychol Soc. 2007;13(3): $450-461$.
38. Mimura M, Yano M. Memory impairment and awareness of memory deficits in early-stage Alzheimer's disease. Rev Neurosci. 2006;17(1-2): 253-266.

39. Hanyu H, Sato T, Akai T, et al. Neuroanatomical correlates of unawareness of memory deficits in early Alzheimer's disease. Dement Geriatr Cogn Disord. 2008;25(4):347-353.

40. Cooke MA, Fannon D, Kuipers E, Peters E, Williams SC, Kumari V. Neurological basis of poor insight in psychosis: a voxel-based MRI study. Schizophr Res. 2008;103(1-3):40-51.

41. Morgan KD, Dazzan P, Morgan C, et al. Insight, grey matter and cognitive function in first-onset psychosis. Br J Psychiatry. 2010;197(2): 141-148.

42. Berge D, Carmona S, Rovira M, Bulbena A, Salgado P, Vilarroya O. Gray matter volume deficits and correlation with insight and negative symptoms in first-psychotic-episode subjects. Acta Psychiatr Scand. 2011;123(6):431-439.

43. Parellada M, Boada L, Fraguas D, et al. Trait and state attributes of insight in first episodes of early-onset schizophrenia and other psychoses: a 2-year longitudinal study. Schizophr Bull. 2011;37(1):38-51.

44. Gerretsen P, Chakravarty MM, Mamo D, et al. Frontotemporoparietal asymmetry and lack of illness awareness in schizophrenia. Hum Brain Mapp. 2013;34(5):1035-1043.

45. Goldberg II, Harel M, Malach R. When the brain loses its self: prefrontal inactivation during sensorimotor processing. Neuron. 2006;50(2): 329-339.

46. Chen ZX, Xue L, Liang CY, et al. Specific marker of feigned memory impairment: the activation of left superior frontal gyrus. J Forensic Leg Med. 2015;36:164-171.

47. Franciotti R, Falasca NW, Bonanni L, et al. Default network is not hypoactive in dementia with fluctuating cognition: an Alzheimer disease/ dementia with Lewy bodies comparison. Neurobiol Aging. 2013;34(4): 1148-1158.

48. Greicius MD, Srivastava G, Reiss AL, Menon V. Default-mode network activity distinguishes Alzheimer's disease from healthy aging: evidence from functional MRI. Proc Natl Acad Sci U S A. 2004; 101(13):4637-4642.

49. Zhang HY, Wang SJ, Liu B, et al. Resting brain connectivity: changes during the progress of Alzheimer disease. Radiology. 2010; 256(2):598-606.

50. Zamboni G, Wilcock G. Lack of awareness of symptoms in people with dementia: the structural and functional basis. Int J Geriatr Psychiatry. 2011;26(8):783-792.

51. Ruby P, Collette F, D'Argembeau A, et al. Perspective taking to assess self-personality: what's modified in Alzheimer's disease? Neurobiol Aging. 2009;30(10):1637-1651.

52. Mograbi DC, Morris RG. On the relation among mood, apathy, and anosognosia in Alzheimer's disease. J Int Neuropsychol Soc. 2014; 20(1):2-7.

53. Starkstein SE, Brockman S, Bruce D, Petracca G. Anosognosia is a significant predictor of apathy in Alzheimer's disease. J Neuropsychiatry Clin Neurosci. 2010;22(4):378-383.

54. Harwood DG, Sultzer DL, Wheatley MV. Impaired insight in Alzheimer disease: association with cognitive deficits, psychiatric symptoms, and behavioral disturbances. Neuropsychiatry Neuropsychol Behav Neurol. 2000;13(2):83-88.

55. Spalletta G, Girardi P, Caltagirone C, Orfei MD. Anosognosia and neuropsychiatric symptoms and disorders in mild Alzheimer disease and mild cognitive impairment. J Alzheimers Dis. 2012;29(4):761-772.

56. Mak E, Chin R, Ng LT, Yeo D, Hameed S. Clinical associations of anosognosia in mild cognitive impairment and Alzheimer's disease. Int J Geriatr Psychiatry. 2015;30(12):1207-1214. 


\section{Publish your work in this journal}

Neuropsychiatric Disease and Treatment is an international, peerreviewed journal of clinical therapeutics and pharmacology focusing on concise rapid reporting of clinical or pre-clinical studies on a range of neuropsychiatric and neurological disorders. This journal is indexed on PubMed Central, the 'PsycINFO' database and CAS, and is the official journal of The International Neuropsychiatric Association (INA). The manuscript management system is completely online and includes a very quick and fair peer-review system, which is all easy to use. Visit http://www.dovepress.com/testimonials.php to read real quotes from published authors.

\footnotetext{
Submit your manuscript here: http://www.dovepress.com/neuropsychiatric-disease-and-treatment-journal
} 